\author{
Associate Professor Irina-Eugenia IAMANDI, PhD \\ E-mail: irina.iamandi@ rei.ase.ro \\ Department of International Business and Economics \\ The Bucharest University of Economic Studies \\ Associate Professor Laura-Gabriela CONSTANTIN, PhD \\ E-mail: laura.constantin@ rei.ase.ro \\ Department of International Business and Economics \\ The Bucharest University of Economic Studies \\ Lecturer Sebastian Madalin MUNTEANU, PhD \\ E-mail: sebastian.munteanu @ase.ro \\ Department of Management \\ The Bucharest University of Economic Studies \\ Lecturer Bogdan CERNAT-GRUICI, PhD \\ E-mail: bogdan.cernat@ rei.ase.ro \\ Department of International Business and Economics \\ The Bucharest University of Economic Studies
}

\title{
PROFILING THE SUSTAINABILITY OF STOCK EXCHANGES AT GLOBAL LEVEL THROUGH AN OPTIMAL SCALING PROCESS BY APPLYING CATPCA
}

\begin{abstract}
The issue of investigating the sustainability of stock exchanges is particularly relevant in the context of sustainable finance. The research objective of the present paper is to analyse the sustainability of stock exchanges based on the construction of an original multi-variate composite index in order to explore the links with business-specific and national environment indicators. We conducted our global study on 92 eligible out of a total of 96 available stock exchanges on the Sustainable Stock Exchanges Initiative (SSE) platform at the end of August 2019. The overall sustainability index of stock exchanges (SustyEx) was developed by successively applying the Categorical Principal Component Analysis (CATPCA) at pillar and aggregated levels. The three-grouping solution highlighted the inclusion of most of the investigated stock exchanges in the initial sustainability development stage. The sustainability achievements of stock exchanges are frequently associated with their internal and external economic performance.

Keywords: Stock Exchanges, Sustainability Index, SSE (Sustainable Stock Exchanges) Initiative, Optimal Scaling, Nonlinear PCA, CATPCA, Sustainable Finance, ESG criteria.
\end{abstract}

JEL Classification: C38, G15, O16, Q01

DOI: $10.24818 / 18423264 / 54.3 .20 .18$ 
Irina-Eugenia Iamandi, Laura-Gabriela Constantin, Sebastian Madalin Munteanu, Bogdan Cernat-Gruici

\section{Introduction}

The sustainability requirements are currently integrated into day-to-day business operations of all corporate agents, reflecting their capacity to competitively develop by equally targeting the economic, social and environmental results. In this context, the need to assess by statistic methods the sustainability of the companies is two-folded. Firstly, it is aimed to illustrate the sustainability efforts of the corporate agents, as a reflection of their contribution to the local development. Secondly, it is intended to objectively evaluate the economicfinancial impact of environmental, social and corporate governance (ESG) endeavours of the companies over the corporate value, in order to increase their competitiveness on the long run.

Apart from the sustainability concerns, the growing trend of sustainable finance is mostly dictated by the investors that are aware of the economic impact of corporate social responsibility (e.g. Smeureanu et al., 2011) and responsible investments and need specific ESG information about their investments (WFE, 2019). The stock exchanges represent an important part of the financial sector and one of the main promoters of sustainable finance at global level. The stock exchanges are fulfilling the requirements of sustainable investors, by supporting the listed companies on ESG disclosure and by offering the needed sustainability information, indices, products, and markets (SSE, 2019b, pp. iv-v; WFE, 2019; Myklebust, 2013). Moreover, it is assumed that stock exchanges and their regulators may fundamentally contribute to the consolidation of integrated reporting and the orientation of capital flows towards more sustainable companies (Eccles and Saltzman, 2011, p. 58).

Most of the papers that investigate the association between sustainability and stock exchanges emphasize the wide contribution of stock exchanges to sustainable development (e.g. Klagge and Zademach, 2018; Myklebust, 2013), specifically to consolidating the ESG involvement of their listed companies, and not the sustainability of stock exchanges per se. However, particularly in the last ten years, the sustainability of stock exchanges has become a relevant topic for investigation, due to the necessity to align the conduct of the capital markets with the public policy goals related to sustainable development (SSE, 2019b, p. viii).

The recent efforts regarding the sustainability of stock exchanges were primarily focused on identifying specific and suitable assessment criteria (SSE, 2019a\&b; WFE 2019; Yow, 2018; Morales and van Tichelen, 2010). In this regard, a key challenge remains the integrative evaluation of stock exchanges' sustainability (e.g. Kalinowski, 2014), an approach that is useful for these institutions to take the lead in sustainable finance and attract responsible investors. Following this challenge, the aim of our research is to comprehensively measure the sustainability of stock exchanges at global level, by developing an innovative composite index and relating it with different corporate and national business

DOI: $10.24818 / 18423264 / 54.3 .20 .18$ 
Profiling the Sustainability of Stock Exchanges at Global Level through an Optimal Scaling Process by Applying CATPCA

indicators. As far as we know, this is one of the first studies systematically assessing the sustainability of stock exchanges at global level.

The five key originality elements of our study are the subsequent: 1 . global-wide study - we considered all the stock exchanges registered on the Sustainable Stock Exchanges Initiative (SSE) platform at the end of August 2019; 2. suitable research methodology - we applied the Categorical Principal Component Analysis (CATPCA) for determining the stock exchanges' sustainability indices, due to the qualitative nature of the data; 3. comprehensive assessment - we developed the concept of stock exchanges' sustainability of SSE by adding new facets from other international organizations (WFE, TCFD) and we proposed an original assessment of the sustainability of stock exchanges; 4 . sustainability-business connection - we associated the achieved stock exchanges' sustainability indices with other SSE corporate and national business indicators; 5 . adequate primary data - we used data that we directly collected by hand and processed it according to our research needs.

For the rest of the paper, the structure is as follows: Section 2 briefly presents a literature review on the assessment of stock exchanges' sustainability; Section 3 deals with our data and research methodology for the development of the sustainability indices and the associations with other corporate and national business variables; Section 4 highlights the results and discussion for the conducted research; and Section 5 is dedicated to the concluding remarks.

\section{Literature Review}

The sustainability of stock exchanges is an ongoing topic on the investigation agenda of sustainable finance at global level. In what concerns the assessment of stock exchanges' sustainability, mainly four research directions may be identified: general, one-directional, criteria-based, and aggregated appraisal.

At general level, World Federation of Exchanges (WFE) explores the nature and extent of stock exchanges' participation in support of various ESG issues, in direct connection with United Nations (UN) Sustainable Development Goals (SDGs) and WFE Sustainability Principles (sustainability education, ESG availability, stake-holders' engagement, development of sustainable financial products and markets, and sustainability inclusion at governance level) (WFE, 2019).

Through one-directional evaluation, the sustainability of stock exchanges is assessed based on one feature of their listed companies (e.g. in Yow (2018), the disclosure of seven sustainability-related indicators).

The criteria-based evaluation is well-developed, especially through the work of UN's Partnership Programme called Sustainable Stock Exchanges Initiative (SSE). SSE is one of the most relevant global organizations investigating the sustain-ability of stock exchanges and its broad positive effects. SSE works for enhancing the stock exchanges' performance on ESG issues and responsible

DOI: $10.24818 / 18423264 / 54.3 .20 .18$ 
Irina-Eugenia Iamandi, Laura-Gabriela Constantin, Sebastian Madalin Munteanu, Bogdan Cernat-Gruici

investments meant to comply with the UN SDGs (SSE, 2019a, 2019b - p. ii). The main SDGs supported by the activities of SSE are: SDG 5 Gender equality, SDG 8 Decent work and economic growth, SDG 10 Reduced inequalities, SDG 12 Responsible consumption and production, SDG 13 Climate action, and SDG 17 Partnerships for the goals (SSE, 2019a). The assessment of stock exchanges' sustainability targets a series of action points/criteria to be checked (SSE partner, annual sustainability report, ESG reporting as a listing rule, written guidance on ESG reporting, ESG training, sustainability index, sustainability bond listing segment, SME listing platform) and a benchmark tool for comparing the sustainable endeavours and ESG performance of stock exchanges (SSE, 2019a\&b).

Using a similar approach, Morales and van Tichelen (2010) examined the internal sustainability concerns of 30 surveyed stock exchanges based on the following issues: CSR/sustainability report, PRI signatories, sustainability indices, sustainability guidance for listing companies, support for trading/development of carbon markets, and involvement in public/private mechanisms for development aid.

The fourth approach - the aggregated appraisal - is about developing composite indices for assessing the multi-variate sustainability of stock exchanges. Kalinowski (2014) proposed a Sustainability Support Index based on four equally weighted variables (ESG disclosure, PRI signatories, sustainability indices, sustainability guidance for listing companies) and investigated the relationship between the size and sustainability of 27 stock exchanges at global level (from SSE). His research revealed no significant correlation between the examined variables.

Based on the existent theoretical and empirical evidence, but also dealing with the current challenges, we aim to develop an original aggregated index for assessing a complex structure of stock exchanges' sustainability by using CATPCA, due to the qualitative nature of the employed data.

Categorical Principal Component Analysis (CATPCA) and index creation. The mainstream literature on index development recognizes Principal Component Analysis and Factor Analysis as established methodologies (OECD, 2008; Greyling and Tregenna, 2017) and is recently flourishing on applying nonlinear approaches when dealing with qualitative data. We further mention some of the studies applying CATPCA. For example, Merola and Baulch (2019) constructed asset indices for provinces in Vietnam and Laos, Saukani and Ismail (2019) identified the components of social capital, Rajesh et al. (2018) developed an inherent vulnerability index for a region in India, Greyling and Tregenna (2017) built a composite index for the quality of life in South Africa, Comim and Amaral (2013) focused on the Brazilian case to aggregate a Human Values Index.

Considering the aforementioned information, the research objective of our study is to analyse the corporate sustainability of stock exchanges at global level. We aim to achieve this goal by developing a comprehensive index to measure the stock exchanges' sustainability and to explore the associations 
Profiling the Sustainability of Stock Exchanges at Global Level through an Optimal Scaling Process by Applying CATPCA

between that index and a series of business-specific and national sustainability indicators.

\section{Data and Methodology}

Our sample consists in 92 stock exchanges globally disposed, selected out of the 96 stock exchanges included in the Sustainable Stock Exchanges Initiative (SSE) database in August 2019, available at https://sseinitiative.org (SSE, 2019a). The database provides updated information on the following sustainability criteria for the included stock exchanges: signing the SSE commitment letter, having annual sustainability report, requiring ESG reporting as a listing rule, having written guidance on ESG reporting, offering ESG related training, having the market covered by sustainability-related index, having sustainability bond listing segment, having SME listing platform, as well as providing additional information on sustainability-related aspects. To achieve a holistic view on the sustainability behaviour of the investigated stock exchanges, we also considered and collected a series of variables (the most recent data up to August 2019) from various sources: responding to World Federation of Exchanges (WFE) sustainability survey in 2019 (WFE, 2019), supporting the Task Force on Climate-related Financial Disclosures (TCFD) in 2019 (fsb-tcfd.org/tcfd-supporters/), ringing the bell for gender equality in 2019 (empowerwomen.org/en/community/events-opportunities/2019/02/2019ring-the-bell-for-gender-equality), participating in SSE global dialogue in 2018, contributing to SSE regulators guidance on Sustainable Development Goals (SDGs) in 2018, contributing to SSE gender equality guidance in 2017, contributing to SSE green finance guidance in 2017, and contributing to SSE model guidance on ESG reporting in 2015 (SSE, 2019a, https://sseinitiative.org/publications/).

Thus, we considered 17 sustainable achievements of the stock exchanges and we further grouped them into three sustainability pillars:

- Awareness - Is SSE Partner, Supports TCFD, Rings the Bell for Gender Equality, Responded to WFE Sustainability Survey, Participated in SSE Global Dialogue;

- Engagement - Contributed to SSE Green Finance Guidance, Contributed to SSE Model Guidance on ESG Reporting, Offers ESG Related Training, Contributed to SSE Regulators Guidance on SDGs, Contributed to SSE Gender Equality Guidance;

- Disclosure, Products \& Markets - Has Annual Sustainability Report, Has Written Guidance on ESG Reporting, Has Sustainability Bond Listing Segment, Reports Additional Sustainability Information, Provides Sustainability Related Index for Market Coverage, Has SME Listing Platform, Requires ESG Reporting as a Listing Rule.

Additionally, we collected the following business-related information about the stock exchanges from the SSE database: country or market of operation, number of listed companies, domestic market capitalization, and organizational model (listed/not listed). The MSCI market classification 
Irina-Eugenia Iamandi, Laura-Gabriela Constantin, Sebastian Madalin Munteanu, Bogdan Cernat-Gruici

(developed/emerging/frontier/ standalone/NA, https://www.msci.com/marketclassification) was also considered, including both the differentiation between developed and not developed markets.

All data was directly collected by authors by hand. We coded most of the sustainability data and the criteria reflecting the status of the stock exchanges and capital markets with 1 (not achieving the criteria/lowest standard) or 2/other maximum value (achieving the criteria/highest standard).

A special case was represented by two distinct variables. We coded the SSE Partner in relation with the year when the stock exchanges signed the commitment: 3 - before 2016, as a reflection of the commitment to sustainability before the adoption of the UN SDGs; 2 - after 2016, as an image of adhering to sustainability desiderata after the adoption of the UN SDGs; and 1 - no SSE Partner, but present in the SSE database. The issue of Reports Additional Sustainability Information (scored from 1 - lowest to 3 - highest sustainability performance) is a subjective variable, which we assessed by analysing every piece of information provided by the stock exchanges in the dedicated section of the SSE database.

Our final sample resulted after filtering the data for transparency (e.g. providing information on the listing status of the stock exchange) and for summing up at least 1 on the sustainability accomplishments, in order to have a homogeneous sample and to elude the risk of biased results (the stock exchanges pertaining to SSE database that do not meet any of our sustainability criteria were eliminated from the analysis because they are similar with those that are not included at all in the list).

Giving the ordinal variables, the methodology consisted in using an optimal scaling process (Categorical Principal Component Analysis - CATPCA) employed in SPSS Statistics and developed in two steps: firstly, for determining the three individual pillars of stock exchanges' sustainability - Sustainability Awareness, Sustainability Engagement, and Sustainability Disclosure, Products \& Markets; secondly, for computing a general index as a reflection of the overall sustainability of the stock exchanges - SustyEx. This two-step approach was inspired by Comim and Amaral (2013). The formation of the overall index was split into two stages as we have already formed the three distinct pillars based on issue resemblance and we wanted to avoid a potential meaningless grouping of the variables.

Like linear principal component analysis (PCA), the process consists in determining the reduced number of linear connections that account for a maximum amount of variance in the analysed data. However, CATPCA is more suitable when investigating data samples that might be characterized by nonlinear relations (as is the case of categorical/qualitative variables) and thus transcends the boundaries of PCA, while also optimally scaling the transformations for the fitted model, as reflected by several canonical works (Meulman, van der Kooij and Heiser, 2004; Meulman, Heiser and SPSS Inc., 2004; Linting et al., 2007; Manisera et al., 2010; 
Profiling the Sustainability of Stock Exchanges at Global Level through an Optimal Scaling Process by Applying CATPCA

Linting and van der Kooij, 2012). Another advantage of this methodology is that we can preserve and account for the ordinal nature of our indicators in terms of sustainable performance (including the case of the dichotomous variables). The VARIMAX with Kaiser normalisation rotation method was also employed for a better outline of the solutions among dimensions.

For the construction of the three sustainability pillars, we conducted three distinct CATPCA for the variables included in each of the three facets. For the overall sustainability index, one CATPCA was run over the ranked values of the newly obtained sustainability pillars (method similar with the one used by Claveria and Poluzzi, 2017). This approach was favoured over a classical averaging scheme for taking advantage of the optimal scaling technique. However, the Pearson correlation coefficient between the average of the three pillars and the overall sustainability score was very high and statistically significant at $1 \%(0.978)$, confirming the fitness of the index.

After examining the solutions for outliers (object scores out of the -3.5 3.5 interval, as recommended in Linting and van der Kooij, 2012), we further considered the total Cronbach's alpha, a communality (the sum of the variance accounted for [VAF] over components for each variable) of at least 0.25 and a VAF per component for each variable of at least 25\% (Comrey's criterion), the scree plots for determining the number of components while also using the criteria of an eigenvalue of at least 1 for each dimension (Kaiser's criterion), and component loadings with a value of at least 0.4 . These criteria are well established in the mainstream literature (Saukani and Ismail, 2019; Linting and van der Kooij, 2012).

Following the approach of Rajesh et al. (2018), the effective computation of each of the four sustainability indices consisted in summing up of the object scores on each dimension (principal component) weighted by the percentage of the variance explained by the corresponding dimension. After computation, both the pillars and the general index are standardized and are analysed as scores with values from 0 to 100, according to Equation (1).

Sustainability $_{\text {Score }}=\frac{\text { Susty Index }-\min (\text { Susty Index })}{\max (\text { Susty Index })-\min (\text { Susty Index })} \times 100$

Once computed the four innovative indices, we developed the analysis around examining the associations between the sustainable performance of the stock exchanges, on the one hand, and their business-related variables (domestic market capitalization, number of listed companies, listing status, MSCI condition) and national sustainable environment related scores (SDG index - sdgindex.org/, SDG Gender index - equalmeasures2030.org/products/sdg-gender-index/, and Environ-mental Performance Index - epi.envirocenter.yale.edu/), on the other hand.

DOI: $10.24818 / 18423264 / 54.3 .20 .18$ 
Irina-Eugenia Iamandi, Laura-Gabriela Constantin, Sebastian Madalin Munteanu, Bogdan Cernat-Gruici

This aim was attained by grouping the stock exchanges in three categories, according to their overall sustainable performance: Low Sustainability Achievers (stock exchanges with scores lower than 33.33), Middle Sustainability Achievers (scores higher than 33.33 and lower than 66.66), and High Sustainability Achievers (scores higher than 66.66). The grouping solution was chosen following the statistical significance of the Jonckheere-Terpstra rank-based nonparametric test (Field, 2017; Laerd Statistics, 2017) over the four sustainability scores after considering several other classifications (based on score values or percentiles). The Jonckheere-Terpstra test was selected over the Kruskal-Wallis as to account for the ordinal characteristic of the groups and, implicitly, to check for a statistically significant trend (Kraska-Miller, 2013). Nonnormality of data (checked with Kolmogorov-Smirnov and Shapiro-Wilk) within each group induced the selection of a nonparametric approach for testing differences in medians among sustainability performances. When the case, we employed ANOVA. The Related Samples Friedman's 2-way ANOVA by ranks test (Field, 2017; Laerd Statistics, 2017) was also employed in various descriptions of the sustainable performance pattern.

\section{Results and Discussions}

The CATPCA model extracted a two-dimensional solution for each of the three sustainability pillars. In what concerns the overall sustainability index of the stock exchanges, the CATPCA model rendered only one dimension/principal component. As already stated, we chose to calculate the final index by employing CATPCA (in the detriment of an average-based method) considering that the overall index is meant to evolve in terms of added variables (like other sustainability indices, e.g. the SDG index) and, consequently, the structure of the nonlinear nexus could change over time. Thus, in order to ensure continuity of determining the future values of the index, we leaned towards the established multivariate analysis.

As reflected by the values displayed in Table 1, the reliability of all four models is high (Cronbach's Alpha), while the percentage of VAF obtained through CATPCA is over $50 \%$. The overall sustainability index of the stock exchanges (SustyEx) reveals a very good representation of the characteristics (more than $75 \%$ ). Moreover, as depicted in Table 2, the first component explains for over $30 \%$, while the second one for over $20 \%$.

Table 1. Summary of the index development CATPCA models (total)

\begin{tabular}{|c|c|c|c|}
\hline CATPCA Model & $\begin{array}{l}\text { Cronbach's } \\
\text { Alpha }\end{array}$ & \multicolumn{2}{|c|}{$\begin{array}{l}\text { Variance Accounted For } \\
\text { (VAF) }\end{array}$} \\
\hline & & $\begin{array}{c}\text { Total } \\
\text { (Eigenvalue) }\end{array}$ & $\%$ of Variance \\
\hline Sustainability Awareness Index & 0.811 & 2.85 & 56.92 \\
\hline Sustainability Engagement Index & 0.827 & 2.96 & 59.10 \\
\hline $\begin{array}{l}\text { Sustainability Disclosure, Products \& } \\
\text { Markets Index }\end{array}$ & 0.861 & 3.81 & 54.46 \\
\hline SustyEx Index & 0.848 & 2.30 & 76.67 \\
\hline
\end{tabular}

DOI: $10.24818 / 18423264 / 54.3 .20 .18$ 
Profiling the Sustainability of Stock Exchanges at Global Level through an Optimal Scaling Process by Applying CATPCA

Figure 1 displays the object scores obtained through CATPCA; these fall into the $-3.5-3.5$ range.

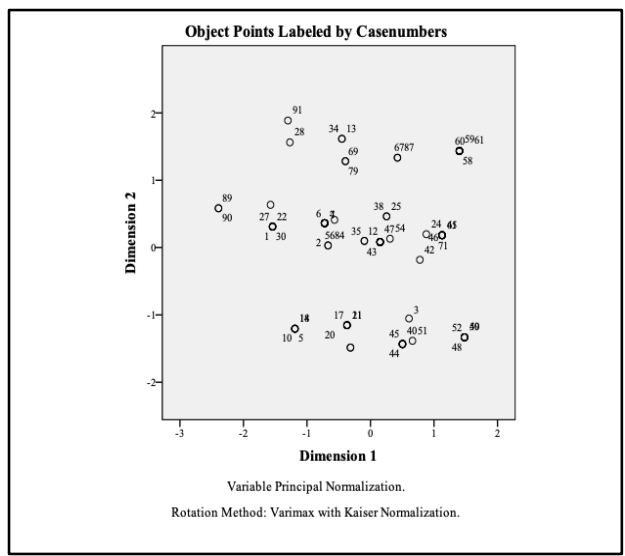

(a) Sustainability Awareness Index

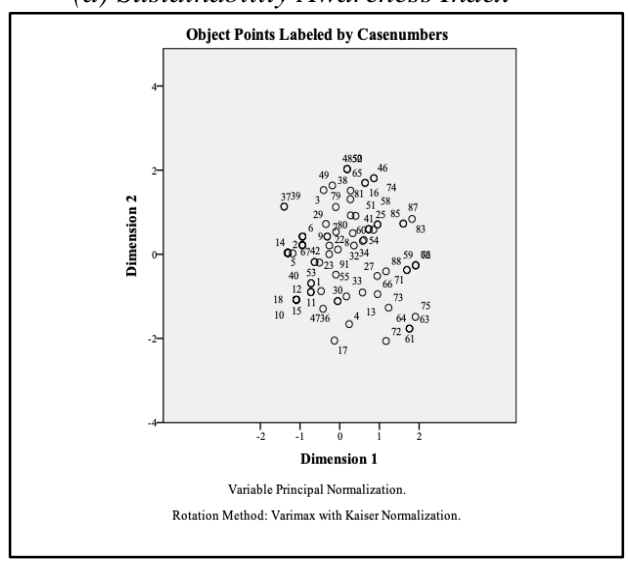

(c) Sustainability Disclosure, Products \& Markets Index

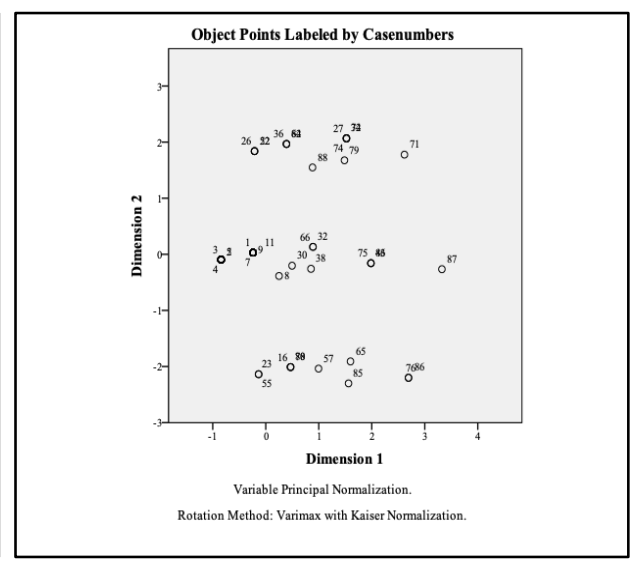

(b) Sustainability Engagement Index

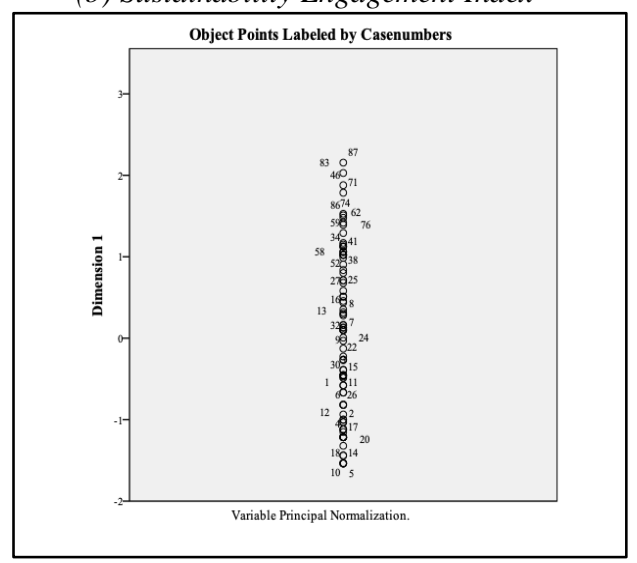

(d) SustyEx Index

Figure 1. The object points from CATPCA

Table 2 displays the rotated solutions (for the three pillars) and unrotated solution (for the overall index, as only one dimension is obtained) for the component loadings and the VAF per dimension for each variable. The highlighted component loadings are higher than 0.4 and positively related to the respective dimension (except for Contributed to SSE Gender Equality Guidance), reflecting the grouping of the sustainability actions for each pillar. For each variable, on the respective grouping dimension, the VAF is above the 0.25 threshold, as well as the total VAF (values in bold). The gathering based on component loadings highlights more specific sustainability behaviours: leading the trend (D1-SA Index),

DOI: $10.24818 / 18423264 / 54.3 .20 .18$ 
Irina-Eugenia Iamandi, Laura-Gabriela Constantin, Sebastian Madalin Munteanu, Bogdan Cernat-Gruici

participating in concept development (D2-SA Index), reporting and supporting (D1-SDPM Index), developing corporate listing (D2-SDPM Index), guiding and training (D1-SE Index), and designing general involvement (D2-SE Index).

Table 2. Rotated component loadings and VAF per dimension from the CATPCA

\begin{tabular}{|c|c|c|c|c|c|}
\hline \multirow[t]{2}{*}{ Variable } & \multicolumn{2}{|c|}{$\begin{array}{l}\text { Component } \\
\text { loadings }\end{array}$} & \multicolumn{3}{|c|}{ VAF } \\
\hline & $D 1$ & D2 & $D 1$ & D2 & Total \\
\hline \multicolumn{6}{|c|}{ Sustainability Awareness Index (SA Index) } \\
\hline Is SSE Partner & 0.787 & -0.085 & 0.620 & 0.007 & 0.627 \\
\hline Supports TCFD & 0.749 & 0.156 & 0.562 & 0.024 & 0.586 \\
\hline Rings the Bell for Gender Equality & 0.584 & 0.104 & 0.341 & 0.011 & 0.352 \\
\hline $\begin{array}{l}\text { Responded to WFE Sustainability } \\
\text { Survey }\end{array}$ & -0.117 & 0.847 & 0.014 & 0.718 & 0.731 \\
\hline Participated in SSE Global Dialogue & 0.307 & 0.675 & 0.094 & 0.456 & 0.550 \\
\hline \multirow{2}{*}{\multicolumn{6}{|c|}{\begin{tabular}{|r|r|r} 
& 32.608 & 24.312 \\
Sustainability Disclosure, Products \& Markets Index (SDPM Index) \\
\end{tabular}}} \\
\hline & & & & & \\
\hline Has Annual Sustainability Report & $\mathbf{0 . 7 8 3}$ & 0.311 & 0.614 & 0.097 & 0.710 \\
\hline $\begin{array}{l}\text { Has Written Guidance on ESG } \\
\text { Reporting }\end{array}$ & 0.732 & 0.012 & 0.536 & 0 & 0.537 \\
\hline $\begin{array}{l}\text { Has Sustainability Bond Listing } \\
\text { Segment }\end{array}$ & 0.695 & -0.374 & 0.483 & 0.14 & 0.623 \\
\hline $\begin{array}{l}\text { Reports Additional Sustainability } \\
\text { Information }\end{array}$ & 0.633 & 0.305 & 0.401 & 0.093 & 0.493 \\
\hline $\begin{array}{l}\text { Provides Sustainability Related Index } \\
\text { for Market Coverage }\end{array}$ & 0.529 & 0.379 & 0.280 & 0.144 & 0.423 \\
\hline Has SME Listing Platform & 0.032 & 0.741 & 0.001 & 0.549 & 0.550 \\
\hline $\begin{array}{l}\text { Requires ESG Reporting as a Listing } \\
\text { Rule }\end{array}$ & 0.148 & 0.674 & 0.022 & 0.454 & 0.476 \\
\hline \multirow{2}{*}{\multicolumn{6}{|c|}{\begin{tabular}{|l|r|} 
& 33.377 \\
Sustainability Engagement Index (SE Index) \\
\end{tabular}}} \\
\hline & & & & & \\
\hline $\begin{array}{l}\text { Contributed to SSE Green Finance } \\
\text { Guidance }\end{array}$ & 0.816 & 0.036 & 0.666 & 0.001 & 0.667 \\
\hline $\begin{array}{l}\text { Contributed to SSE Model Guidance } \\
\text { on ESG Reporting }\end{array}$ & 0.720 & -0.100 & 0.518 & 0.010 & 0.528 \\
\hline Offers ESG Related Training & $\mathbf{0 . 5 8 7}$ & 0.067 & 0.345 & 0.005 & 0.349 \\
\hline $\begin{array}{l}\text { Contributed to SSE Regulators } \\
\text { Guidance on SDGs }\end{array}$ & 0.454 & 0.713 & 0.206 & 0.508 & 0.714 \\
\hline $\begin{array}{l}\text { Contributed to SSE Gender Equality } \\
\text { Guidance }\end{array}$ & 0.468 & -0.691 & 0.219 & 0.478 & 0.697 \\
\hline & & & 39.074 & 20.028 & 59.103 \\
\hline \multicolumn{6}{|c|}{ SustyEx Index } \\
\hline Rank of SDPM Index & 0.909 & & 0.825 & & 0.825 \\
\hline Rank of SA Index & 0.866 & & 0.749 & & 0.749 \\
\hline Rank of SE Index & 0.852 & & 0.725 & & 0.725 \\
\hline & & & 76.667 & & 76.667 \\
\hline
\end{tabular}

Table 3 shows the descriptive statistics of the sustainability scores (Sustain-ability Awareness - SA, Sustainability Engagement - SE, Sustainability 
Profiling the Sustainability of Stock Exchanges at Global Level through an Optimal Scaling Process by Applying CATPCA

Disclosure, Products \& Markets - SDPM, Overall Sustainability - SustyEx) of the stock exchanges. The highest average values are reached by the SA Score and the lowest by the SE Score, indicating that stock exchanges realize the importance of adhering to sustainability principles, but they are rather low contributors to sustainability guidance for the moment. A more insightful analysis considers the Related Samples Friedman's 2-way ANOVA by ranks test applied to the three pillars for the overall sample. The sustainability performance is found to be statistically different between the SE Score and SA Score and between the SE Score and SDPM Score.

Table 3. Descriptive statistics of the investigated stock exchanges Sustainability scores and specific business variables

\begin{tabular}{|l|r|r|r|r|r|r|r|}
\hline Indicator & \multicolumn{1}{c|}{ Mean } & \multicolumn{1}{c|}{ Median } & \multicolumn{1}{c|}{ Min. } & \multicolumn{1}{c|}{ Max. } & \multicolumn{1}{c|}{ Std. Dev. } & Kurt. & Skew. \\
\hline SA Score & 45.81 & 42.75 & 0.00 & 100.00 & 27.45 & -0.33 & 0.40 \\
\hline SE Score & 26.10 & 21.54 & 0.00 & 100.00 & 23.64 & 0.96 & 1.35 \\
\hline SDPM Score & 43.07 & 40.91 & 0.00 & 100.00 & 28.82 & -1.25 & 0.17 \\
\hline SustyEx Score & 41.63 & 43.11 & 0.00 & 100.00 & 27.18 & -1.08 & 0.17 \\
\hline $\begin{array}{l}\text { Listed } \\
\text { companies (no.) }\end{array}$ & 564.95 & 182.00 & 1.00 & $5,616.00$ & 980.70 & 8.75 & 2.80 \\
\hline $\begin{array}{l}\text { Domestic market } \\
\text { capitalization } \\
\text { (mil. } \text { USD) }\end{array}$ & $960,303.04$ & $79,232.00$ & 1.00 & $22,081,367.00$ & $2,742,794.29$ & 40.46 & 5.81 \\
\hline
\end{tabular}

Figure 2 reflects the distribution of the stock exchanges along the three sustainability clusters. There is a relative homogenous distribution of the stock exchanges within each cluster. Although significant sustainability achievements were recently registered by the stock exchanges at global level (SSE, 2019b; WFE, 2019), the highest number of entities is still included in the low performance cluster. This result indicates that the sustainability presence at operating level is still in an initial phase and the coming advancements should mainly deal with the role that stock exchanges may have in guiding the listed companies and regulators in strategically including ESG/sustainability criteria into their business models.

DOI: $10.24818 / 18423264 / 54.3 .20 .18$ 
Irina-Eugenia Iamandi, Laura-Gabriela Constantin, Sebastian Madalin Munteanu, Bogdan Cernat-Gruici

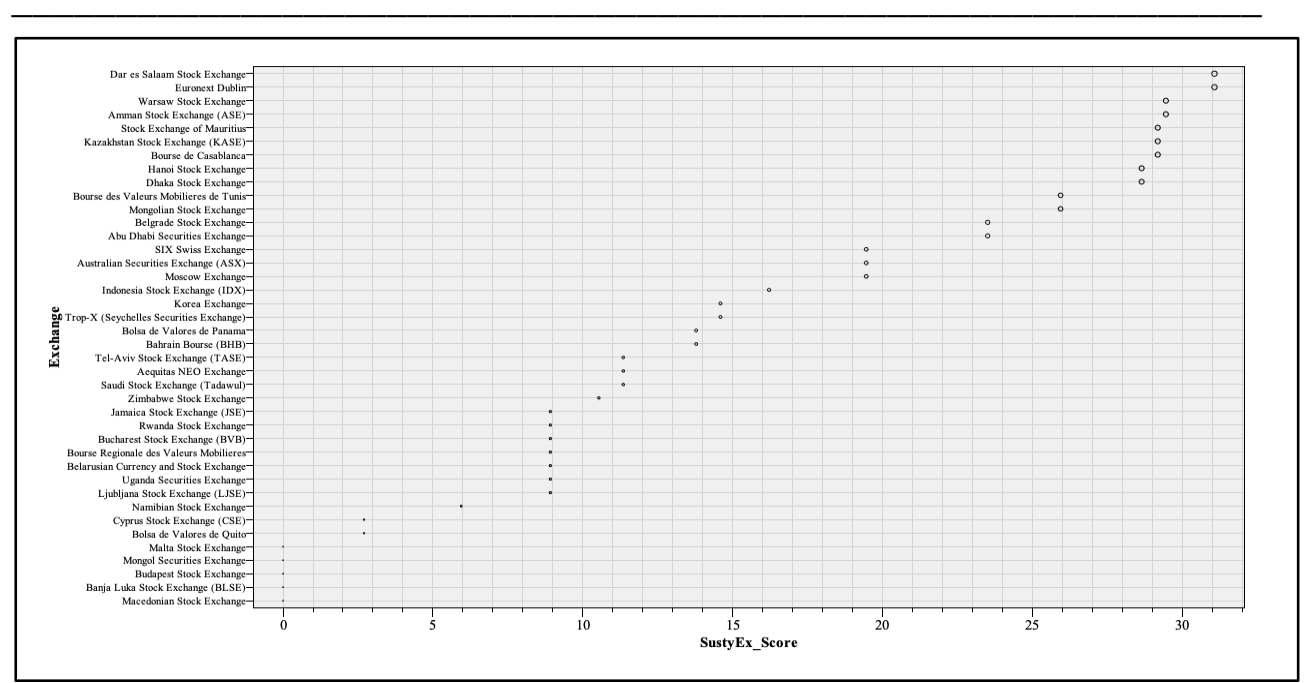

(a) Low Sustainability Achievers

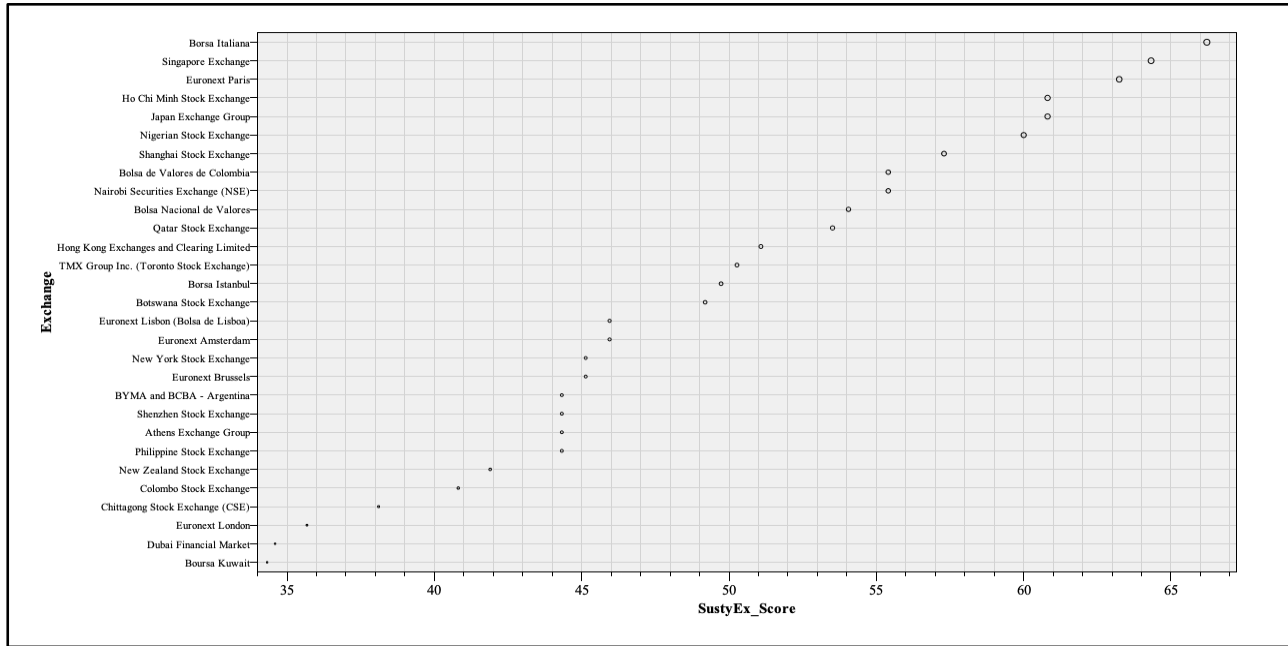

(b) Middle Sustainability Achievers 
Profiling the Sustainability of Stock Exchanges at Global Level through an Optimal Scaling Process by Applying CATPCA

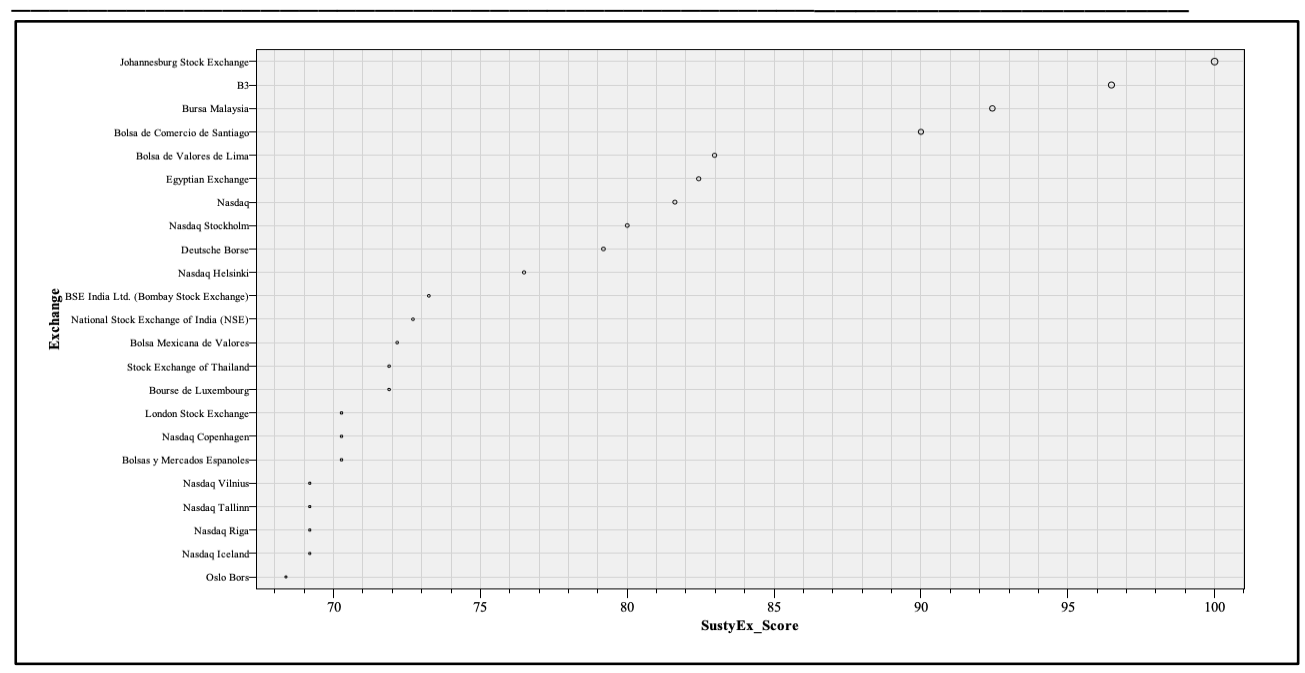

(c) High Sustainability Achievers

Figure 2. Stock exchanges' sustainability scores

Table 4 outlines the performance of the sustainability scores for each sustainable group. The Low Sustainability Achievers - the largest group - follow the pattern of the overall sample (the lowest performance for engagement activities, the highest performance for awareness achievements). The other two groups exhibit the lowest performance for sustainability engagement pursuits, but the highest for sustainability disclosure, products and markets accomplishments. For a more robust insight on the relation between the three scores within each group, we performed the Friedman test and the Pairwise comparisons accompanied by a Bonferroni correction reflected the following: for Low Sustainability Achievers, the sustainability performance was statistically different between the SE and SA Scores; for Middle Sustainability Achievers, the sustainability performance was statistically different between the SE and SA Scores, but also between the SE and SDPM Scores; for High Sustainability Achievers, the sustainability performance was statistically different between the SE and SA Scores, as well as between the SE and SDPM Scores.

Table 4. Descriptive statistics of the stock exchanges' sustainability groups across the SustyEx Scores

\begin{tabular}{|c|c|c|c|c|c|}
\hline $\begin{array}{c}\text { Stock } \\
\text { exchanges' } \\
\text { sustainability } \\
\text { groups }\end{array}$ & Indicator & $\begin{array}{c}\text { Sustainability } \\
\text { Awareness } \\
\text { (SA) Score }\end{array}$ & $\begin{array}{c}\text { Sustainability } \\
\text { Engagement } \\
\text { (SE) Score }\end{array}$ & $\begin{array}{l}\text { Sustainability } \\
\text { Disclosure, } \\
\text { Products \& } \\
\text { Markets } \\
\text { (SDPM) Score }\end{array}$ & $\begin{array}{c}\text { SustyEx } \\
\text { Score }\end{array}$ \\
\hline \multirow{4}{*}{$\begin{array}{c}\text { Low } \\
\text { Sustainability } \\
\text { Achievers } \\
\text { (40 stock }\end{array}$} & Mean & 25.88 & 10.65 & 17.54 & 15.36 \\
\hline & Median & 26.72 & 7.40 & 15.02 & 13.78 \\
\hline & Min. & 0.00 & 0.00 & 0.00 & 0.00 \\
\hline & $\operatorname{Max}$. & 59.92 & 41.16 & 56.52 & 31.08 \\
\hline
\end{tabular}

DOI: $10.24818 / 18423264 / 54.3 .20 .18$ 
Irina-Eugenia Iamandi, Laura-Gabriela Constantin, Sebastian Madalin Munteanu, Bogdan Cernat-Gruici

\begin{tabular}{|c|l|r|r|r|r|}
\hline exchanges) & Std. Dev. & 17.28 & 8.35 & 12.10 & 10.36 \\
\hline Middle & Mean & 46.04 & 28.63 & 52.95 & 49.52 \\
\cline { 2 - 6 } Sustainability & Median & $\mathbf{5 0 . 3 8}$ & $\mathbf{2 1 . 5 4}$ & $\mathbf{5 4 . 9 4}$ & $\mathbf{4 9 . 1 9}$ \\
\cline { 2 - 6 } Achievers & Min. & 17.18 & 7.40 & 0.00 & 34.32 \\
\cline { 2 - 6 }$(29$ stock & Max. & 76.72 & 79.74 & 84.58 & 66.22 \\
\cline { 2 - 6 } exchanges) & Std. Dev. & 14.12 & 19.21 & 21.59 & 9.07 \\
\hline \multirow{3}{*}{ High } & Mean & 80.19 & 49.77 & 75.00 & 77.37 \\
\cline { 2 - 6 } Sustainability & Median & $\mathbf{7 3 . 2 8}$ & $\mathbf{5 5 . 3 1}$ & $\mathbf{7 7 . 0 8}$ & $\mathbf{7 2 . 7 0}$ \\
\cline { 2 - 6 } Achievers & Min. & 50.38 & 14.15 & 51.38 & 68.38 \\
\cline { 2 - 6 } (23 stock & Max. & 100.00 & 100.00 & 100.00 & 100.00 \\
\cline { 2 - 6 } exchanges) & Std. Dev. & 19.38 & 26.27 & 14.24 & 9.48 \\
\hline
\end{tabular}

The pairwise analysis following the Jonckheere-Terpstra test of trend (Table 5.a.) confirms an upward trend in medians for all the sustainability scores along the sustainability achievers' groups. Though mostly confirming an upward trend along the MSCI criteria and listing status groups, the sustainability scores differentiate typically among extreme clusters. When considering other businessrelated and national sustainability indicators as dependent variables in differentiating between Low, Middle, and High Sustainability Achievers groups (Table 5.b.), the distinctive pattern confirms the significant trend in medians between the extreme groups in most of the cases (there are only two exceptions).

The results in Table 5 highlight that the sustainability engagement actions of the investigated stock exchanges are rather homogenous when considering the listing status and the capital market development, indicating that stock exchanges should further strengthen their sustainability guidance and training role for companies, investors and even regulators. Besides, the specific social (SDG Gender Index) and eco-friendly (Environmental Performance Index) accomplishments at national level do not differentiate between the stock exchanges' sustainability groups, confirming that the sustainability achievements of these organizations are rather associated with internal and external economic performance.

Table 5. Pairwise analysis results after Jonckheere-Terpstra test for the sustainability scores

\begin{tabular}{|c|c|c|c|c|}
\hline \multicolumn{5}{|c|}{ Table 5.a. } \\
\hline \multirow[b]{2}{*}{$\begin{array}{c}\text { Stock } \\
\text { exchanges, } \\
\text { sustainability } \\
\text { scores as } \\
\text { dependent } \\
\text { variables }\end{array}$} & \multicolumn{4}{|c|}{ Grouping/Independent variable } \\
\hline & $\begin{array}{c}\text { SustyEx Score } \\
\text { Low/ } \\
\text { Middle/ } \\
\text { High } \\
\text { Sustainability } \\
\text { Achievers } \\
\end{array}$ & $\begin{array}{l}\text { MSCI criteria } \\
\text { Developed/ } \\
\text { Not developed }\end{array}$ & $\begin{array}{c}\text { MSCI criteria } \\
\text { Developed (D)/ } \\
\text { Emerging (E)/ } \\
\text { Frontier (F)/ } \\
\text { Standalone (SA)/ } \\
\text { Not assigned (NA) }\end{array}$ & $\begin{array}{l}\text { Listing status } \\
\text { Listed/ } \\
\text { Not listed }\end{array}$ \\
\hline $\begin{array}{l}\text { Sustainability } \\
\text { Awareness } \\
\text { Score }\end{array}$ & $\begin{array}{l}\text { Significant trend in } \\
\text { medians between } \\
\text { all three groups }\end{array}$ & $\begin{array}{l}\text { Significant trend in } \\
\text { medians between } \\
\text { the two groups }\end{array}$ & $\begin{array}{l}\text { Significant trend in } \\
\text { medians between } \\
\text { NA and D groups }\end{array}$ & $\begin{array}{l}\text { Significant trend in } \\
\text { medians between } \\
\text { the two groups }\end{array}$ \\
\hline $\begin{array}{l}\text { Sustainability } \\
\text { Engagement }\end{array}$ & $\begin{array}{l}\text { Significant trend in } \\
\text { medians between }\end{array}$ & $\begin{array}{l}\text { No significant trend } \\
\text { in medians }\end{array}$ & $\begin{array}{l}\text { Significant trend in } \\
\text { medians between }\end{array}$ & $\begin{array}{l}\text { No significant trend } \\
\text { in medians }\end{array}$ \\
\hline
\end{tabular}


Profiling the Sustainability of Stock Exchanges at Global Level through an Optimal Scaling Process by Applying CATPCA

\begin{tabular}{|c|c|c|c|c|}
\hline Score & all three groups & & NA and E groups & \\
\hline $\begin{array}{l}\text { Sustainability } \\
\text { Disclosure, } \\
\text { Products \& } \\
\text { Markets Score }\end{array}$ & $\begin{array}{l}\text { Significant trend in } \\
\text { medians between } \\
\text { all three groups }\end{array}$ & $\begin{array}{l}\text { Significant trend in } \\
\text { medians between } \\
\text { the two groups }\end{array}$ & $\begin{array}{l}\text { Significant trend in } \\
\text { medians between } \\
\text { NA and D, NA and } \\
\text { E, SA and D, F } \\
\text { and D groups } \\
\end{array}$ & $\begin{array}{l}\text { Significant trend in } \\
\text { medians between } \\
\text { the two groups }\end{array}$ \\
\hline SustyEx Score & $\begin{array}{l}\text { Significant trend in } \\
\text { medians between } \\
\text { all three groups }\end{array}$ & $\begin{array}{l}\text { Significant trend in } \\
\text { medians between } \\
\text { the two groups }\end{array}$ & $\begin{array}{l}\text { Significant trend in } \\
\text { medians between } \\
\text { NA and D, NA and } \\
\text { E, F and D groups }\end{array}$ & $\begin{array}{l}\text { Significant trend in } \\
\text { medians between } \\
\text { the two groups }\end{array}$ \\
\hline \multicolumn{5}{|c|}{ Table 5.b. } \\
\hline \multirow{2}{*}{\multicolumn{2}{|c|}{$\begin{array}{c}\text { Other business-related and } \\
\text { national sustainability indicators } \\
\text { as dependent variables }\end{array}$}} & \multicolumn{3}{|c|}{ Grouping/Independent variable } \\
\hline & & \multicolumn{3}{|c|}{$\begin{array}{c}\text { SustyEx Score } \\
\text { Low (L)/ Middle (M)/ High (H) Sustainability Achievers }\end{array}$} \\
\hline \multicolumn{2}{|c|}{ Number of listed companies } & \multicolumn{3}{|c|}{ Significant trend in medians between $\mathbf{L}$ and $\mathbf{H}$ groups } \\
\hline \multicolumn{2}{|c|}{ Domestic market capitalization } & \multicolumn{3}{|c|}{$\begin{array}{l}\text { Significant trend in medians between } \mathbf{L} \text { and } \mathbf{H} \text { and } \mathbf{L} \text { and } M \\
\text { groups }\end{array}$} \\
\hline \multicolumn{2}{|c|}{$\begin{array}{l}\text { MSCI criteria } \\
\text { Developed/Not developed }\end{array}$} & \multicolumn{3}{|c|}{$\begin{array}{l}\text { Significant trend in medians between } \mathbf{L} \text { and } \mathbf{H} \text { and } \mathbf{L} \text { and } \mathbf{M} \\
\text { groups }\end{array}$} \\
\hline \multicolumn{2}{|c|}{$\begin{array}{l}\text { MSCI criteria } \\
\text { Developed/Emerging/ Frontier/ } \\
\text { Standalone/ Not assigned }\end{array}$} & \multicolumn{3}{|c|}{$\begin{array}{l}\text { Significant trend in medians between } \mathbf{L} \text { and } \mathbf{H} \text { and } \mathbf{L} \text { and } \mathbf{M} \\
\text { groups }\end{array}$} \\
\hline \multicolumn{2}{|l|}{$\begin{array}{l}\text { Listing status } \\
\text { Listed/Not listed }\end{array}$} & \multicolumn{3}{|c|}{ Significant trend in medians between $\mathbf{L}$ and $\mathbf{H}$ groups } \\
\hline \multicolumn{2}{|l|}{ SDG Index } & \multicolumn{3}{|c|}{ Significant trend in medians between $\mathbf{L}$ and $\mathbf{H}$ groups } \\
\hline \multicolumn{2}{|c|}{ SDG Gender Index } & \multicolumn{3}{|c|}{ No significant difference in means } \\
\hline \multicolumn{2}{|c|}{ Environmental Performance Index } & \multicolumn{3}{|c|}{ No significant trend in medians } \\
\hline
\end{tabular}

\section{Conclusions}

Based on an innovative multi-criterial composite index, the present research underlined the existence of different sustainability behaviours of stock exchanges at global level. The sustainability of stock exchanges has an evolutive nature and is still in the initial phase, with significant achievements recently registered especially on the awareness side (leading the trend and participating in concept development). In the coming period, the focus of sustainable stock exchanges should be on engagement issues, by guiding the listed companies and responsible investors on the ESG inclusion. The study also revealed that not specifically the social or ecological advancements of the external environment, but the different facets of economic performance of the stock exchanges are the engines of their sustainability.

Further research could consider a larger number of stock exchanges and more variables to be included in the overall sustainability index, when data becomes available. Moreover, the research could be replicated in the future to test for the consistency or evolution of the results.

\section{DOI: $10.24818 / 18423264 / 54.3 .20 .18$}


Irina-Eugenia Iamandi, Laura-Gabriela Constantin, Sebastian Madalin Munteanu, Bogdan Cernat-Gruici

\section{REFERENCES}

[1] Claveria, O., Poluzzi, A. (2017), Positioning and Clustering of the World's Top Tourist Destinations by Means of Dimensionality Reduction Techniques for Categorical Data. Journal of Destination Marketing \& Management, 6(1): 22-32; [2] Comim, F., Amaral, P.V. (2013), The Human Values Index: Conceptual Foundations and Evidence from Brazil. Cambridge Journal of Economics, 37(6): 1221-1241;

[3] Eccles, R.G., Saltzman, D. (2011), Achieving Sustainability through Integrated Reporting. Stanford Social Innovation Review, Summer 2011: 56-61; [4] Field, A. (2017), Discovering Statistics Using IBM SPSS Statistics, 5th Ed. London, UK: SAGE Publications;

[5] Greyling, T., Tregenna, F. (2017), Construction and Analysis of a Composite Quality of Life Index for a Region of South Africa. Social Indicators Research, 131(3): 887-930;

[6] Kalinowski, M. (2014), Stock Exchanges Sustainability Support Assessment. Copernican Journal of Finance \& Accounting, 3(2): 37-48;

[7] Klagge, B., Zademach, H.M. (2018), International Capital Flows, Stock Markets, and Uneven Development: The Case of Sub-Saharan Africa and the Sustainable Stock Exchanges Initiative (SSEI). Zeitschrift für Wirtschaftsgeographie (The German Journal of Economic Geography), 62(2): 92-107; [8] Kraska-Miller, M. (2013), Nonparametric Statistics for Social and Behavioral Sciences. Taylor \& Francis Group, LLC, Chapman and Hall/CRC. [9] Laerd Statistics (2017), Jonckheere-Terpstra Test Using SPSS Statistics. Statistical Tutorials and Software Guides. Available at: https://statistics.laerd.com/; [10] Linting, M., van der Kooij, A. (2012), Nonlinear Principal Components Analysis with CATPCA: A Tutorial. Journal of Personality Assessment, 94(1): 1225;

[11] Linting, M., Meulman, J.J., Groenen, P.J.F., van der Kooij, A.J. (2007), Nonlinear Principal Components Analysis: Introduction and Application. Psychological Methods, 12(3): 336-358;

[12] Manisera, M., van der Kooij, A.J., Dusseldorp, E. (2010), Identifying the Component Structure of Satisfaction Scales by Nonlinear Principal Components Analysis. Quality Technology \& Quantitative Management, 7(2): 97-115;

[13] Merola, G.M., Baulch, B. (2019), Using Sparse Categorical Principal Components to Estimate Asset Indices: New Methods with an Application to Rural Southeast Asia. Review of Development Economics, 23(2): 640-662; [14] Meulman, J.J., Heiser, W.J., SPSS Inc. (2004), SPSS Categories 13.0. Chicago, USA: SPSS. Available at:

http://java.mcmaster.ca/SPSS.manual/SPSS\%20Categories\%2013.0.pdf; 
Profiling the Sustainability of Stock Exchanges at Global Level through an Optimal Scaling Process by Applying CATPCA

[15] Meulman, J.J., van der Kooij, A.J., Heiser, W.J. (2004), Principal Components Analysis with Nonlinear Optimal Scaling Transformations for Ordinal and Nominal Data. Chapter in book: The SAGE Handbook of Quantitative Methodology for the Social Sciences, Sage Publications, 49-72;

[16] Morales, R., van Tichelen, E. (2010), Sustainable Stock Exchanges: Real Obstacles, Real Opportunities. Discussion paper prepared for the Sustainable Stock Exchanges 2010 Global Dialogue. Report prepared by Responsible Research. Available at:

http://archive.longfinance.net/images/reports/pdf/rr_suststockexchanges_2010.pdf; [17] Myklebust, T. (2013), The Role of Stock Exchanges in Shaping More Sustainable Company and Market Practices, September 12, 2013. University of Oslo Faculty of Law Research Paper No. 2013-28; Nordic \& European Company Law Working Paper No. 10-41. Available at: https://ssrn.com/abstract=2324743; [18] OECD (2008), Handbook on Constructing Composite Indicators. Methodology and User Guide. Paris, France: OECD Publications. Available at: https://www.oecd.org/sdd/42495745.pdf (accessed on August 15, 2019); [19] Rajesh, S., Jain, S., Sharma, P. (2018), Inherent Vulnerability Assessment of Rural Households Based on Socio-Economic Indicators Using Categorical Principal Component Analysis: A Case Study of Kimsar Region, Uttarakhand. Ecological Indicators, 85(Feb.2018): 93-104;

[20] Saukani, N., Ismail, N.A. (2019), Identifying the Components of Social Capital by Categorical Principal Component Analysis (CATPCA). Social Indicators Research, 141(2): 631-655;

[21] Smeureanu, I., Dioșteanu, A., Delcea, C., Cotfas, L. (2011), Business Ontology for Evaluating Corporate Social Responsibility. Amfiteatru Economic, 13(29): 28-42;

[22] Sustainable Stock Exchanges Initiative (SSE) (2019a). Available at: https://sseinitiative.org/ (accessed on August 01, 2019);

[23] Sustainable Stock Exchanges Initiative (SSE) (2019b), 10 Years of Impact and Progress. Sustainable Stock Exchanges 2009-2019. Available at: https://sseinitiative.org/wp-content/uploads/2019/12/SSE-10-year-impactreport.pdf (accessed on December 19, 2019);

[24] World Federation of Exchanges (WFE) (2019), WFE Sustainability Survey April 2019. Exchanges Advancing Sustainable Finance. Available at: https://www.world-exchanges.org/our-work/articles/wfe-sustainability-surveyapril-2019 (accessed on August 15, 2019); [25] Yow, M. (2018), Nasdaq Helsinki Leads Ranking of World's Stock Exchanges on Sustainability Disclosure, November 5, 2018. Available at: https://www.corporateknights.com/reports/2018-world-stock-exchanges/helsinkileads-ranking-worlds-stock-exchanges-sustainability-disclosure-15414364/ (accessed on September 15, 2019).

DOI: $10.24818 / 18423264 / 54.3 .20 .18$ 